\title{
Correction of diabetic pattern of insulin release from islets of the spiny mouse (Acomys cahirinus) by glucose priming in vitro
}

\author{
R. Nesher, E. Abramovitch and E. Cerasi \\ Department of Endocrinology and Metabolism, The Hebrew University Hadassah Medical Center, Jerusalem, Israel
}

\begin{abstract}
Summary. Insulin release kinetics were studied in perifused islets of Langerhans, isolated from mildly hyperglycaemic and from normoglycaemic spiny mice (Acomys cahirinus), a rodent predisposed to develop spontaneously non-ketotic diabetes. In both groups, insulin response to glucose $(16.7 \mathrm{mmol} / \mathrm{l})$ was delayed in comparison with that of rat islets, the release kinetics being analogous to that of human Type 2 (non-insulin-dependent) diabetes. Thirty min priming of the isolated Acomys islets with glucose $(16.7 \mathrm{mmol} / \mathrm{l})$ resulted in potentiation of the insulin release to a second stimulation. The degree of potentiation decreased exponentially with the time interval between stimulations, showing a $t^{1 / 2}$ of $18 \mathrm{~min}$. Induction of potentiation by glucose was time-dependent, giving a maximal effect after $20 \mathrm{~min}$ of priming. In addition to overall amplification of the insulin response, priming with glucose accelerat-
\end{abstract}

ed markedly the initial release rates, correcting the dynamics of the response. We conclude that: (1) decreased and delayed insulin secretion is found in Acomys cahirinus before the development of hyperglycaemia; (2) induction of time-dependent potentiation in the islet by priming with glucose corrects the diabetic-type dynamics of insulin release; (3) therefore the deficient insulin release of Acomys is of a functional nature, the mechanism of potentiation bypassing the defect; (4) since insulin release in Acomys resembles that in prediabetic and diabetic man, similar conclusions might apply to the islet dysfunction in Type 2 diabetes.

Key words: Insulin secretion, time-dependent potentiation, non-insulin dependent-diabetes, Acomys cahirinus.
Glucose intolerance and hyperglycaemia in Type 2 diabetes are the result of an inappropriate pancreatic response to changes in the blood glucose level, accompanied by some decrease in peripheral response to insulin [1]. The inappropriate pancreatic response is characterized by reduction in the sensitivity of $\beta$ cells to glucose and delay or absence of the acute insulin response [2-7]. To elucidate the metabolic defect(s) of the $\beta$ cells, suitable animal models for Type 2 diabetes are needed. The spiny mouse (Acomys cahirinus) is a semi-desert rodent which has been studied extensively as a model for Type 2 diabetes in man [8-16]. Bred in captivity, these animals demonstrate various degrees of glucose intolerance, become obese with age and develop hyperglycaemia. At all stages of glucose intolerance, whether obese or lean, bred in captivity or newly captured, the spiny mouse exhibits decreased insulin response to glucose stimulation, both in vivo and in vitro $[10-14,16]$.

Studies in recent years demonstrated that apart from initiating immediate insulin release, glucose generates a time-dependent state of potentiation in the islets of Langerhans, which leads to the amplification of insulin secretion upon subsequent stimulation [17-22]. The present study examines the effect of such glucose priming on insulin release in the islets of spiny mice and demonstrates that it corrects the diabetic pattern of insulin secretion.

\section{Materials and methods}

Islets of Langerhans were isolated by collagenase digestion (Serva Feinbiochemica, Heidelberg, FRG) [23] from non-fasted male rats (5-7 weeks old Sabra HUC strain) weighing 150-200 g, and from adult hyperglycaemic or normoglycaemic Acomys cahirinus. All animals were bred and raised at the Hebrew University animal farm and maintained on free laboratory chow diet. Two groups of spiny mice, age 4-9 months, were used: the hyperglycaemic animals $(n=37)$ had a morning (non-fasting, prior to killing) mean plasma glucose of $9.2 \pm 0.7 \mathrm{mmol} / 1 \mathrm{compared}$ with $5.6 \pm 0.2 \mathrm{mmol} / 1$ in the normoglycaemic Acomys $(n=16)$. The mean morning plasma glucose level in the fed rats was $7.8 \pm 0.2 \mathrm{mmol} / 1(n=10)$.

The isolated islets were washed at $4 \mathrm{C}$ in oxygen-saturated Hanks solution supplemented with glucose $(5.5 \mathrm{mmol} / 1)$, and suspended at $4 \mathrm{C}$ in basal Krebs-Ringer-bicarbonate buffer containing glucose $3.3 \mathrm{mmol} / \mathrm{l}$. Thirty to fifty islets were transferred into a perifusion chamber $(70 \mu \mathrm{l})$ and perifused at $37 \mathrm{C}$ at a flow rate of $1.0 \mathrm{ml} / \mathrm{min}$ 


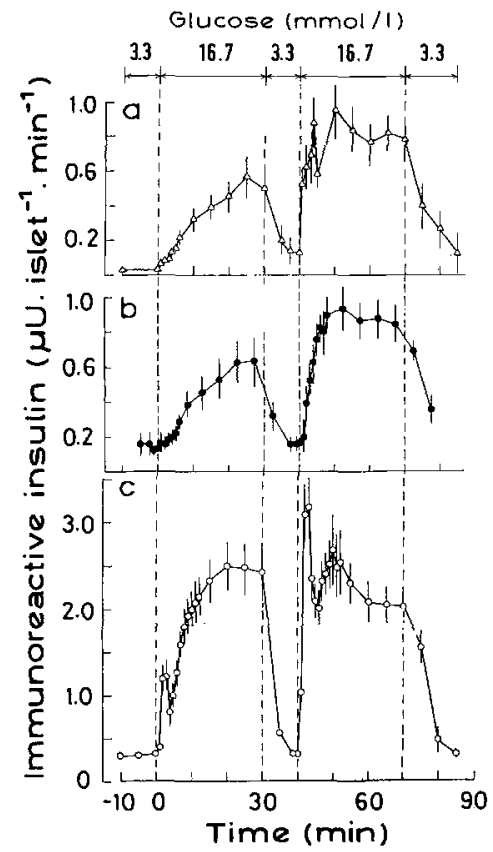

Fig. 1. Dynamics of insulin release from islets of Langerhans isolated from a hyperglycaemic Acomys, b normoglycaemic Acomys and $\mathbf{c}$ rats. Each point is the mean of nine experiments with hyperglycaemic Acomys, five experiments with normoglycaemic Acomys and 11 experiments with rat islets. Bars $=$ mean \pm SEM

with basal Krebs-Ringer bicarbonate buffer gassed with $\mathrm{O}_{2}(95 \%)$ and $\mathrm{CO}_{2}(5 \%)$. Following $40 \mathrm{~min}$ of perifusion with basal buffer, the perifusate was changed to buffer containing glucose either 16.7 or $3.3 \mathrm{mmol} / 1$ for the times indicated in the specific experiments outlined.

Acomys and rat immunoreactive insulin levels were determined in the perifusate by radioimmunoassay [13] using $20 \%$ polyethylene glycol for separation of bound ligand from free hormone. Human insulin was used as reference standard for Acomys islets and rat insulin for rat islets. The reference insulins were obtained from Novo Research Institute, Bagsvaerd, Denmark. The minimal detectable dose in the insulin assay was $1-3 \mu \mathrm{U} / \mathrm{ml}$, the intraassay C.V. was $5.7 \%$ and the interassay C.V. was $8.8 \%$. Plasma glucose levels were determined by the glucose oxidase method using a Glucose Analyzer 2 (Beckman Instruments Co., Fullerton, California).

\section{Results}

Although Acomys islets appear larger in size than rat islets, there was no significant difference in their insulin content. Islet insulin content in 10 animals from each group (not used for perifusion) was $35 \pm 6 \mathrm{ng}$ /islet in rats; $25 \pm 7 \mathrm{ng}$ /islet in hyperglycaemic Acomys and $22 \pm 6 \mathrm{ng} /$ islet in normoglycaemic Acomys.

An abrupt increase in the concentration of perifusate glucose from 3.3 to $16.7 \mathrm{mmol} / 1$ resulted in a slow insulin response in Acomys islets, devoid of the typical first-phase dynamics (Fig. 1).

Normoglycaemic Acomys islets resembled islets of hyperglycaemic Acomys dynamics regarding insulin release, with the exception of lower basal secretion rates in the latter. For comparison, the normal dynamics of

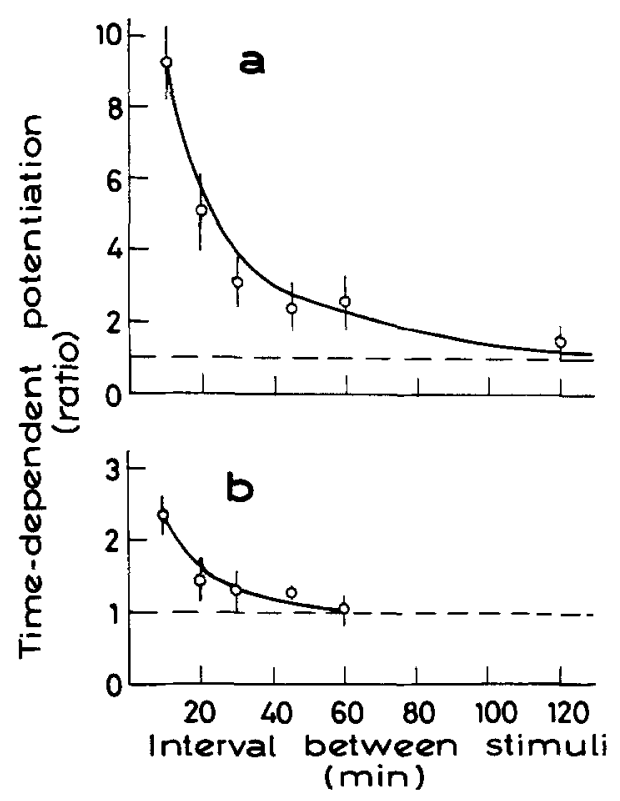

Fig. 2. Duration of time-dependent potentiation induced by glucose in islets of hyperglycaemic Acomys. The magnitude of potentation is expressed as the ratio [amount of insulin released during the second period] $\div$ [that released during the first period of stimulation]. a early response (first $6 \mathrm{~min}$ ), b late response (final $24 \mathrm{~min}$ ). The biological $\mathrm{t}^{1 / 2}$ of the potentiating effect of glucose was estimated to be $18 \mathrm{~min}$ in both early and late responses. Mean $\pm S E M$ of four to nine observations

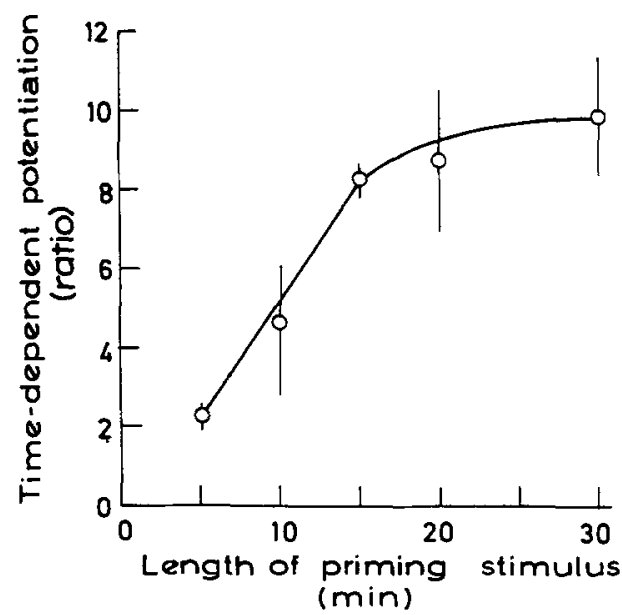

Fig. 3. Effect of duration of the priming perifusion with glucose $(16.7 \mathrm{mmol} / 1)$ on time-dependent potention of insulin release in islets of hyperglycaemic Acomys. The effect of the duration of priming is expressed as the ratio of the amount of insulin released during the initial $6 \mathrm{~min}$ of the second period of stimulation over that found during the initial $6 \mathrm{~min}$ period of priming with glucose $(16.7 \mathrm{mmol} / \mathrm{l})$. Each point represents four to eight observations. Mean \pm SEM is shown

insulin release from isolated rat islets are presented in Figure 1. An abrupt change in perifusate glucose concentration from 3.3 to $16.7 \mathrm{mmol} / 1$ resulted in an immediate response in rat islets with a typical frist-phase peak within $2-3 \mathrm{~min}$, followed by a nadir in the release rate at 5-6 $\mathrm{min}$, and a prompt rise to a second phase of insulin secretion thereafter. 
Following the first $30-\mathrm{min}$ period of stimulation with high glucose, the perifusate glucose concentration was reduced to $3.3 \mathrm{mmol} / 1$ for $10 \mathrm{~min}$, allowing the insulin secretion rates to return towards baseline. When stimulated a second time with glucose $(16.7 \mathrm{mmol} / 1)$, insulin secretion from both normoglycaemic and hyperglycaemic Acomys islets was strongly amplified: the sluggish early rate of insulin release seen during the initial stimulus was markedly accelerated during the second stimulus (Fig.1). Although the peak insulin response was still somewhat delayed in comparison with that of rat islets, the diabetic pattern of secretion was markedly improved. The effect of glucose priming on late insulin release was smaller but significant when calculated over the final $24 \mathrm{~min}$ of stimulation (2.4-fold increase in hyperglycaemic Acomys and 2.2-fold in normoglycaemic Acomys islets).

The time characteristics of the potentiating state induced by the glucose priming were investigated in islets from hyperglycaemic Acomys: two 30-min glucose stimuli $(16.7 \mathrm{mmol} / \mathrm{l})$ were applied separated by a basal perifusion (glucose $3.3 \mathrm{mmol} / \mathrm{l}$ ), the duration of which varied. The degree of potentiation was expressed as the ratio of the second insulin response to the first. Maximal potentiation of both early and late insulin responses was obtained when the time interval between stimuli was $10 \mathrm{~min}$ (Fig. 2). With increasing time, the magnitude of the potentiation induced by the glucose priming decreased exponentially, the half-life of the effect both on early and late insulin release being around $18 \mathrm{~min}$.

A full 30-min stimulation was not necessary to generate the priming effect of glucose. Even a 5-min glucose priming was sufficient to double the early insulin response during a second stimulus given $10 \mathrm{~min}$ later (Fig. 3). Under these conditions, a maximally potentiating effect was observed following priming with glucose for $20 \mathrm{~min}$.

\section{Discussion}

This study deals with the dynamics of insulin secretion in a rodent with predisposition to mild, non-ketotic hyperglycaemia [9]. Except for a slight difference in the basal insulin secretion rate, both the kinetics and the magnitudes of the insulin responses to glucose were comparable whether islets were obtained from hyperglycaemic or from normoglycaemic Acomys, and the sluggishness and reduced amplitude of the response resembled findings in vivo in patients with Type 2 diabetes [2-7]. We have previously described low and sluggish insulin responses in some normoglycaemic human subjects, who on prospective study were shown to develop glucose intolerance with a high incidence [24, 25]. The present findings suggest that a similar situation may exist in Acomys cahirinus. It was indeed shown in a previous study [16] that when insulin resistance was in- duced in Acomys by dietary measures, the insulin secretion of the animals was not substantially augmented, and consequently hyperglycaemia developed. Thus, the normoglycaemic Acomys, whose islets have sluggish insulin response to glucose, may represent a model for prediabetes, namely individuals with increased risk of developing diabetes.

The facts that the diabetic-type kinetics of the insulin response can be demonstrated in Acomys in vivo as well as in vitro, and that there is an excellent correlation between the insulin response of individual animals in vivo and the insulin secretion rates in vitro of the islets isolated from the same animals [12], indicate that the deranged insulin secretion is an inherent characteristic of the islet of Langerhans in this species. It has been suggested that an anatomical defect might be responsible for the deficient insulin release in Acomys [8]. The present study clearly indicates that the defect must be of a functional nature, since priming of the islets with glucose in vitro rapidly restored almost normal secretion dynamics.

As shown in this study and in previous reports [17-22, 26, 27], glucose priming induces in normal islets a time-dependent potentiating memory, which amplifies the insulin response to subsequent stimuli. The nature of the intracellular message generated by the glucose priming is unknown. The time-course studies presented here show that the effect of glucose priming has a fairly long half-life $(18 \mathrm{~min})$ and thus contrasts sharply with the rapid disappearance of the acute insulin stimulatory effect of glucose when the hexose is withdrawn. Studies in man $[19,27]$, and in vitro using the perfused rat pancreas $[20,21]$, have shown that inhibition of the insulin response to glucose during priming does not prevent the generation of a time-dependent potentiation. The present findings support our earlier conclusion [20] that the effects of glucose on acute insulin release and on generation of a potentiating state in the islet are distinct and separable. Thus, while the stimulus-secretion coupling of glucose-induced acute insulin release is defective in the islets of spiny mice, the mechanism responsible for time-dependent potentiation is not impaired.

One important conclusion from this study, as well as from earlier studies in mildly diabetic man [28], is that the defective stimulus-secretion coupling in a diabetic islet can be corrected: the mechanism of glucose-induced time-dependent potentiation can bypass the block in insulin secretion. If this potentiation operates also in vivo, it may serve as a compensatory mechanism and reduce the severity of the insulin deficit (hence of the hyperglycaemia). That this assumption may be correct is suggested by the finding of a normal glucose-induced potentiation in mild human diabetes, but not in more severe hyperglycaemia [1].

Analogies between human diabetes and any animal model of the disease call for caution. Nevertheless, the numerous similarities between mild non-insulin depen- 
dent diabetes and patients with low insulin response on the one hand, and hyperglycaemic and normoglycaemic Acomys on the other hand, make the spiny mouse a most attractive model for use in investigating some of the biochemical events in the islet that lead to the development of diabetes.

Acknowledgments. The excellent technical assistance of S. Epstein is greatly appreciated. We wish to thank M.Pick and G. Lebedeva for the insulin radioimmunoassay and L. Granot for preparing the manuscript. This work was supported in part by grant R01 AM21598-MET from the National Institutes of Health (NIADDK), a grant from the Israel Ministry of Health, Chief Scientist's Office, and a grant from the Juvenile Diabetes Foundation.

\section{References}

1. Efendic S, Wajngot A, Cerasi E, Luft R (1980) Insulin release, insulin sensitivity and glucose intolerance. Proc Natl Acad Sci USA 77: 7425-7429

2. Perley M, Kipnis DM (1966) Plasma insulin responses to glucose and tolbutamide of normal weight and obese diabetic subjects. Diabetes 15: 867-874

3. Cerasi E, Luft R (1963) Plasma-insulin response to sustained hyperglycaemia induced by glucose infusion in human subjects. Lancet 2: 1359-1361

4. Cerasi E, Luft R, Efendic S (1972) Decreased sensitivity of the pancreatic beta cells to glucose in prediabetic and diabetic subjects. A glucose dose-response study. Diabetes 21: 224-234

5. Seltzer HS, Allen EW, Herron AH, Brennon MT (1967) Insulin secretion in response to glycemic stimulus: relation of delayed initial release to carbohydrate intolerance in mild diabetes. J Clin Invest $46: 323-335$

6. Kipnis DM (1970) Insulin secretion in normal and diabetic individuals. Adv Intern Med 16: 103-108

7. Pfeifer MA, Halter JB, Porte D (1981) Insulin secretion in diabetes mellitus. Am J Med 70: 579-588

8. Cameron D, Stauffacher W, Renold AE (1972) Spontaneous hyperglycemia and obesity in laboratory rodents. In: Steiner DF, Freinkel N (eds) Handbook of physiology, Section 7: Endocrinology. American Physiological Society, Washington, DC. pp 611-625

9. Gonet AE, Stauffacher W, Pictet R, Mougin J, Renold AE (1965) Obesity and diabetes mellitus with striking congenital hyperplasia of islets of Langerhans in spiny mice (Acomys cahirinus). Diabetologia 1: 162-171

10. Gutzeit A, Rabinovitch A, Studer PP, Trueheart PA, Cerasi E, Renold AE (1974) Decreased intravenous glucose tolerance and low plasma insulin response in spiny mice (Acomys cahirinus). Diabetologia 10: 667-670

11. Rabinovitch A, Gutzeit A, Grill V, Kikuchi M, Renold AE, Cerasi E (1975) Defective insulin secretion in the spiny mouse (Acomys cahirinus). Possible value in the study of the pathophysiology of diabetes. Isr J Med Sci 11: 730-737

12. Rabinovitch A, Gutzeit A, Renold AE, Cerasi E (1975) Insulin secretion in the spiny mouse (Acomys cahirinus). Dose and time kinetic studies with glucose in vivo and in vitro. Diabetes 24: 1094-1100
13. Rabinovitch A, Gutzeit A, Kikuchi M, Cerasi E, Renold AE (1975) Defective early phase insulin release in perifused isolated islets of spiny mice (Acomys cahirinus). Diabetologia 11:457-465

14. Cerasi E, Jeanrenaud B (1979) Glucose production by the perfused liver of the spiny mouse (Acomys cahirinus): sensitivity to glucagon and insulin. Ist J Med Sci 15: 134-139

15. Grill V, Cerasi E (1979) The metabolism of cyclic AMP and glucose in isolated islets from Acomys cahirinus. Diabetologia 16: $47-50$

16. Gutzeit A, Renold AE, Cerasi E, Shafrir E (1979) Effect of diet induced obesity on glucose and insulin tolerance of a rodent with a low insulin response (Acomys cahirinus). Diabetes 28: 777-784

17. Grodsky GM, Curry D, Landahl H, Bennett LL (1969) Further studies on the dynamic aspects of insulin release in vitro with evidence for a two compartmental storage system. Acta Diabet Lat 6 (Suppl 1): 554-579

18. Cerasi E (1975) Potentiation of insulin release by glucose in man. I. Quantitative analysis of the enhancement of glucose-induced insulin secretion by pretreatment with glucose in normal subjects. Acta Endocrinol 79: 483-501

19. Cerasi E (1975) Potentiation of insulin release by glucose in man. II. Role of the insulin response and enhancement of stimuli other than glucose. Acta Endocrinol 79:502-510

20. Grill V, Adamson U, Cerasi E (1978) Immediate and time-dependent effects of glucose on insulin release from rat pancreatic tissue. Evidence for different mechanisms of action. J Clin Invest 61: 1034-1043

21. Grill V, Adamson U, Rundfeldt M, Andersson S, Cerasi E (1979) Glucose memory of pancreatic B and A cells: evidence for common time-dependent actions of glucose on insulin and glucagon secretion in perfused rat pancreas. J Clin Invest 64: 700-707

22. Grill V (1981) Time and dose dependencies for priming effect of glucose on insulin secretion. Am J Physiol 240: E24-E31

23. Lacy PE, Kostianovsky M (1967) Method for the isolation of intact islets of Langerhans from the rat pancreas. Diabetes 16:35-39

24. Cerasi E, Luft R (1974) Follow-up of non-diabetic subjects with normal and decreased insulin response to glucose infusion. Horm Metab Res (Suppl 5) 113-120

25. Wajngot A (1983) Aspects on the pathogenesis of Type 2 diabetes. Thesis, Karolinska Institute, Stockholm

26. Ashby JP, Shirling D (1980) Evidence for priming and inhibitory effect of glucose on insulin secretion from isolated islets of Langerhans. Diabetologia 18: 417-421

27. Efendic S, Lins PE, Cerasi E (1979) Potentiation and inhibition of insulin release in man following priming with glucose and with arginine - effect of somatostatin. Acta Endocrinol 90: 259-271

28. Cerasi E (1975) Potentiation of insulin release by glucose in man. III. Normal recognition of glucose as a potentiator in subjects with low insulin response and in mild diabetes. Acta Endocrinol 79: $511-534$

Received: 30 January 1984

and in revised form: 25 February 1985

Dr. Rafael Nesher

Department of Endocrinology and Metabolism

Hadassah Medical Center

P.O. Box 12000

Jerusalem 91120 , Israel 